\title{
Cabis, guacas-fortalezas y el control incaico del valle de Aconcagua
}

\author{
Rubén Stehberg ${ }^{1}$ y Gonzalo SotomayoR ${ }^{2}$
}

\section{RESUMEN}

Se postula a partir de información arqueológica e histórica temprana que en el Período Agroalfarero Tardío preincaico, la población nativa del valle de Aconcagua se encontraba agrupada en torno a Cabis, teniendo a la vista un cerro sagrado --cerro Tren-Tren-- ${ }^{3}$ y al mando de un cacique principal. El control incaico del valle se habría efectuado mediante la apropiación del mencionado cerro y la construcción en el lugar de una guaca-fortaleza. Se ejemplifica con los casos del cerro Mercachas y el dominio del Cabi de Curimón en las tierras altas y, el de cerro Mauco y la intervención del Cabi de Puchun en las tierras bajas.

\begin{abstract}
Based on early historical and archaeological information, we state that in the pre-incaic Late Pottery-agricultural Period, the native population of the Aconcagua valley was grouped around a Cabi, having a sacred hill (Tren-Tren hill) in its range of sight, and was commanded by a main cacique. The incaic control of the valley could have taken place by means of the appropriation of the mentioned hill and the construction of a guacafortress at this location. Examples of it are the cases of Mercachas hill and the dominion on the Cabi of Curimón in te highlands, and the case of cerro Mauco and the intervention of the Cabi of Puchun in the lowlands.
\end{abstract}

1 Museo Nacional de Historia Natural. Santiago, Chile. Email: rstehberg@mnhn.cl

2 Londres 65. Santiago. Email: gsotomay@puc.cl

\section{Introducción}

El año 1997 se dio inicio a investigaciones arqueológicas sobre el período Tawantinsuyu o Período de Contacto Incaico en el curso medio-superior del valle de Aconcagua, teniendo como punto de partida el sector de Salto El Soldado y como eje articulador el Camino Inca Trasandino y sus instalaciones asociadas (Stehberg et al. 1999). Este proyecto contó con el apoyo económico del Fondo Nacional de Ciencia y Tecnología, FONDECYT (Proyecto $N^{\circ} 1970068$ ). (Figura 1)

Tras un año de investigación y luego de visitar la mayoría de los sitios arqueológicos y revisar la totalidad de las colecciones del período depositadas en el Museo Arqueológico de Los Andes, surgió la necesidad de complementar esta información con antecedentes procedentes de la documentación histórica temprana, es decir siglos XVI y comienzos del XVII. Ante la inexistencia de estudios publicados sobre el particular en el área de interés se consultó al historiador local René León por documentación inédita de archivo. Este nos puso en contacto con su colega Gonzalo

\footnotetext{
3 El mito mapuche del diluvio universal señala que las serpientes kai-kai y tren-tren compiten entre sí. La primera eleva el nivel de las aguas. Los hombres se refugian en la cima de un cerro alto donde la serpiente tren-tren lo hace crecer a medida que las aguas suben. Esta competencia continúa hasta que el cerro se acerca al sol, donde la cabeza de los hombres se quema dando origen a la calvicie. Se produce un sacrificio que marca el inicio del descenso de las aguas y de los cerros hasta el punto que tienen ahora. Este diluvio puede repetirse y por tanto cada parcialidad mapuche elige un cerro tren-tren donde refugiarse en caso de que el fenómeno vuelva a ocurrir.
} 


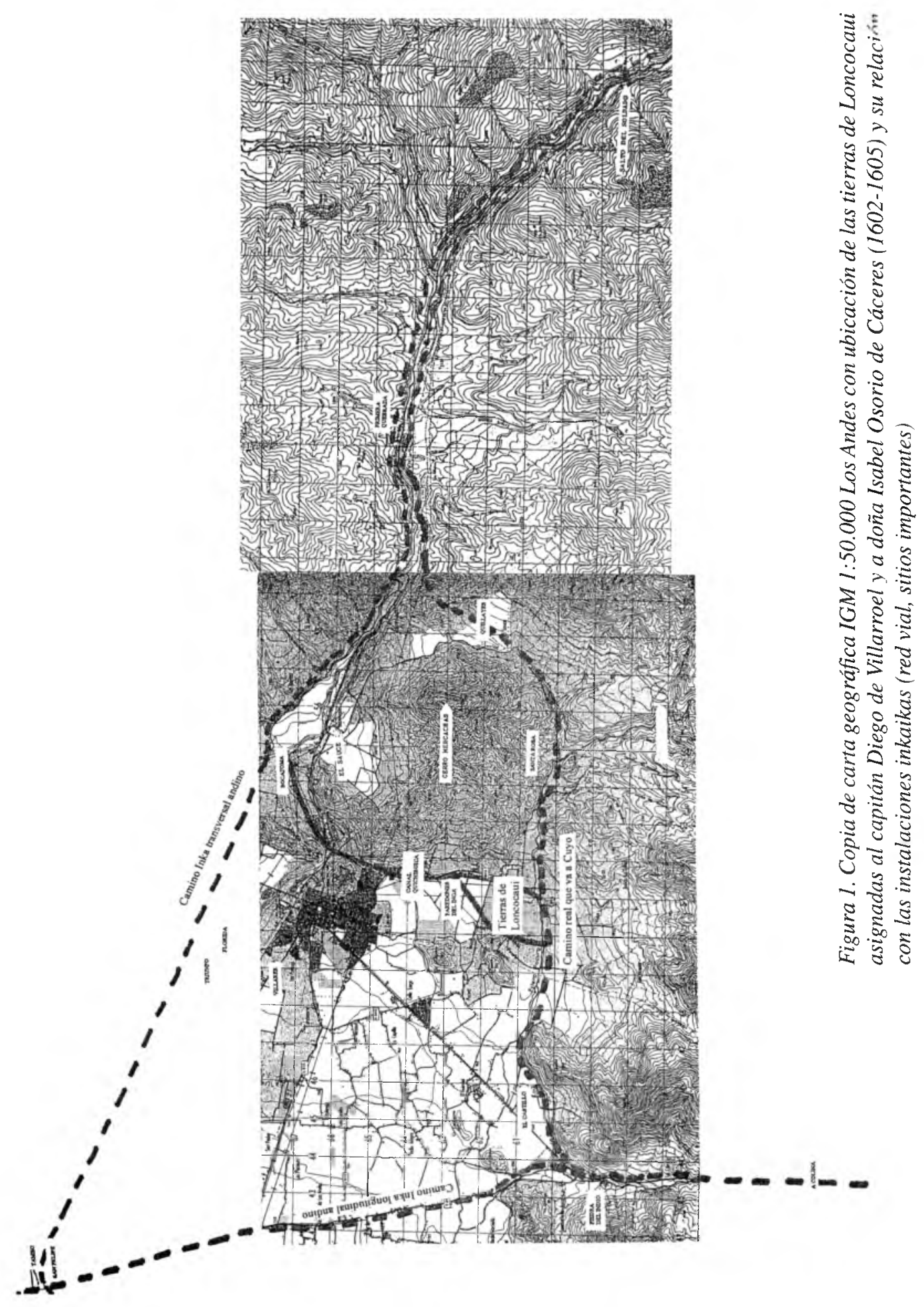


Sotomayor, quien a la sazón se encontraba realizando estudios documentales sobre los Pueblos de Indios de Curimón y Aconcagua.

Tras una reunión, Sotomayor aceptó incorporarse al proyecto, haciéndose cargo de la búsqueda de material inédito relativo a los primeros documentos judiciales existentes en los valles recién mencionados de Curimón y Aconcagua y su correspondiente transcripción paleográfica, mientras que la localización geográfica de las mercedes de tierra, y su análisis e interpretación serían abordados interdisciplinariamente por el arqueólogo y el historiador.

Se decidió iniciar los trabajos con el análisis de los títulos de merced y mensura de las tierras asignadas al capitán Diego de Villarroel, entre 1602 y 1605 , por tratarse de uno de los primeros españoles en asentarse en este sector del valle y en un área que tuvo gran importancia para el Tawantinsuyu a juzgar por la monumentalidad de algunos sitios (Mercachas, El Castillo y cementerio de Santa Rosa), la vialidad estatal y la relevancia de sus artesanías (San Vicente, El Sauce) (Stehberg y Coros 1999). Pese a la información aportada por la arqueología, ésta era insuficiente como para plantear un modelo explicativo que diera cuenta de lo que allí estaba pasando durante el Período de Contacto Incaico.

Los resultados obtenidos (Stehberg et al. 1998) proporcionaron valiosa información respecto a los siguientes aspectos:

- Deslindes de la merced de tierra con sus principales hitos y el nombre de sus propietarios vecinos.

- Los caciques que la ocuparon.

- La ubicación probable de una importante instalación incaica denominada "Paredones del Inga". - El trazado de la acequia indígena Quechibuica, su eventual origen incaico y su preservación hasta el presente como canal de Los Maquis.

- La delimitación del Camino Real a Cuyo, coincidente con el trazado del camino trasandino incaico, por la margen izquierda del estero Pocuro. - La toponimia y patronimia indígena de fines del siglo XVI y el significado etimológico de alguno de ellos.

- La diversidad étnica de sus ocupantes indígenas basada en el origen mapudungun, quechua y kun$z a$ de algunos apellidos.

Estos resultados enriquecieron sustancialmente nuestros conocimientos sobre el sector, al señalar que el Tawantinsuyu erigió una instalación arquitectónica en el sector de Santa Rosa, abrió un gran canal de riego (acequia Quichibuica) que seguía en uso durante el siglo XVII, atravesó mediante un camino el sector del estero Pocuro y, proporcionó el topónimo de Loncaguin, transcripto por Carlos Ruiz (1998:120), como Longko kawiñ fiesta del longko, o fiesta de la cabeza o cabeza de la parcialidad. Sin embargo, la información proporcionada no fue suficiente para formular el modelo explicativo buscado.

El hallazgo de un nuevo documento inédito, donde otra importante personalidad de la época reclama para sí 700 cuadras de tierra que incluyen las de Diego de Villarroel, entrega valiosa información que complementa la anterior y que luego de analizada permite formular una hipótesis que explicaría la importancia del sector y el mecanismo utilizado por el Tawantinsuyu para controlar simbólica y políticamente el área.

Cabe destacar, en este lugar, el aporte fundamental que ha tenido en la construcción de esta interpretación el Dr. Ian Farrington, arqueólogo australiano y especialista en simbolismo incaico, a través de sus múltiples artículos (1992, 1998, 1999) y de sus explicaciones en terreno en el lago Titicaca, Cusco, Valle Sagrado y el propio valle de Aconcagua.

A continuación se transcribe paleográficamente el documento, se analizan sus partes más relevantes, se describe arqueológicamente el área y se finaliza con la discusión y planteo del mencionado modelo.

\section{Documento analizado}

El cuerpo documental analizado corresponde a una merced de tierra de 700 cuadras otorgada por el Gobernador Alonso García Ramón en el año de 1605 a doña Isabel Osorio de Cáceres en el valle de Curimón, en tierras llamadas Longo Cabi y Panguey (Biblioteca Nacional Sala Medina, $\mathrm{Ar}$ chivo Barros Arana, vol 8. Tomo BA-8). 
Esta merced incluye prácticamente la totalidad de las tierras otorgadas al capitán Diego de Villarroel, lo cual generó un problema jurídico posterior. Doña Isabel traspasó el 9 de noviembre de 1609 sus tierras a los padres Agustinos. En este legajo se insertó una petición efectuada por el procurador agustino padre Bartolomé de Arenas en que se solicitó fueran lanzados los herederos del capitán Diego de Villarroel (Pedro de Villarroel, Alonso de Escobar y doña Ana Mariño de Lobera) y otros, dado que estas tierras habían sido cedidas al convento como parte de una capellanía y que les pagasen los frutos que hubiesen producido las dichas tierras (Figura 2).

\section{Transcripción paleográfica}

fs.. 38

Alonso Garcia Ramon gobernador capitan gene(ral) y justicia mayor deste rreyno e prouincias de Chille por el rey nuestro señor. Por quanto doña Ysabel Ossorio de Cazeres fue ligitima muger del cap(it)an Rramiro Yanez de Sarauia difunto que sirbio a su magestad en es te reyno muchos años y por su fin y muerte la susodicha tiene nesse sidad me ha pedido le haga m(er)d de algunas tierras para labrança y cria de ganados y que en el ualle de Curimon terminos de la ciudad de Santiago ay tierras vacas en que le pueda dar la $\mathrm{d}$ (ic)ha m(erce)d considerando los suso(ich)os?

...Por la presente en n(ombr)e de su mag(esta)d real y ussan do de su rreall poder y comisiones que como tal gob(ernado)r capitan general y justicia mayor tengo hago m(erce)d a bos la d(ic)ha doña Ysabel Ossorio de Cazeres para bos y para buestros her(eder)os y sub ssessores y para quien de bos obiere caussa de setesientas quadras de tierras cumplidas y acauadas en el d(ic)ho valle de Curimon nom bradas longocaui y Pagueu que fueron del cacique don $\mathrm{Al}$ (ons)o $\mathrm{Ru}$ bio y de Calquintegua difuntos o las que ubiere en el dicho sitio despues de medidas trezientas quadras que tiene en el d(ic)ho balle el capitann Diego de Villarroel y corran con la serra nia que tienen las $\mathrm{d}(\mathrm{ic}) \mathrm{has}$ tierras por las espaldas hasta el serro llamado Colurquen y de largo hasta los paredones del In ga llamadas Curapilu y tierras del capitan Mena que sson a la parte de Anconcagua y de la parte de zur el camino que ba desta c(iud)d a Cuyo y la cordillera que junto a ellas esta de la parte de Curemon lindan con una acequia anti gua y tierras que heran del cacique don $\mathrm{Al}$ (ons)o Millanaume y della parte del Norte una acequia y tierras de don Juan Pirulay y el estero y agua que ba por medio destas d(ic)has tierras se llama Pucuro y tierras que .... tenia el cacique Liaronco y sus su jetos con los $\mathrm{d}$ (ic)hos nombres o por otros qualquiera que tengan las quales deslindadas y declaradas os doy sin perjuicio de los yndios del $\mathrm{d}(\mathrm{ic})$ ho valle ni de otro tercero..... para que sean buestras propias para los efetos ..... y de buestros subssesores y de ellas y en ellas podais haser lo que quisiere del y por bien tubiere del como de cossa buestra propia auida con justo titulo y os la doy graciossamente sin ninguna pension ni obligacion con todas sus entra das y salidas usos y costumbres...seruidumbres quanta ay tienen...

derecho de uso y costumbre y encargo y mando a qual 


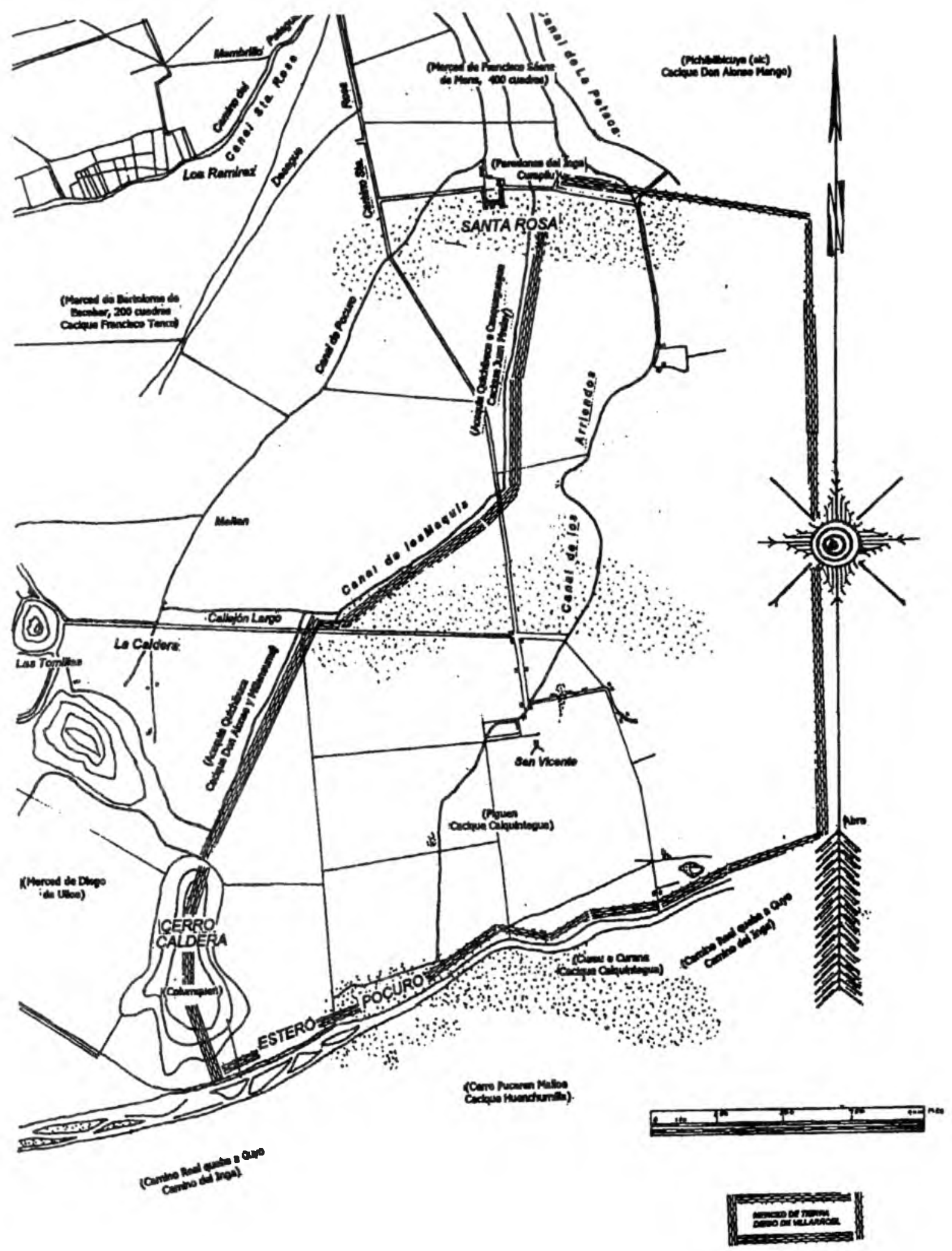

Figura 2. Copia del extremo SE del "Plano de los terrenos que riega el Canal Sta. Rosa", Los Andes, 1909, levantado por Pedro Ant. Pérez L., con indicación entreparéntesis de los topónimos y nombres de topónimos y antropónimos que figuran en los títulos de la merced de Isabel Osorio de Cáceres 


\section{fs. 39}

quier jues o juezes de est rreyno a quien pidiese aga?

la possesion a las dichas tierras que luego que con este

mimandamiento y titulo sean requeridos os den y hagan

dar la possesion rreal actual corporal valcaci de las

$\mathrm{d}$ (ic)has tierras conforme a d(erech)o so pena de qui(inetos) pesos de oro

para la camara de su mag(esta)d y gastos deguerra por mitad

Echo en la ciudad de la Cosecion a veynte y ocho dias del mes

de Mayo de mill y seis cientos cinco años

\section{Posesión}

[rubrica]

Alonso G(rarc)ia

Ramon

Por mandado del gobernador

Lorenzo del Salto

En el asiento de Curimon tierras llamadas Longo Cabi y y Pigueu terminos y juridicion de la ciudad de Sant(iago en tres

dias del mes de Setiembre de seiscientos y cinco años parescio

Garcia Her(nande)z de Caceres presbitero antel cap(it)an don Rodrigo de Ro

jas corregidor y just(ici)a Maior deste dicho balle en nombre de do

ña Ysauel Osorio de Caceres y por uirtud de su poder que hi

ço demostracion pidio y requirio al dicho cap(it)an don Ro

drigo de Rojas quen virtud de la m(erce)d hecha a su parte por su

señoria del señor gouernadorAl(ons)o Garcia Ramon le diese

y metiese en la posecion de setecientas cuadras en el

titulo nombradas y pidio just(ici)a y bisto por su m(erce)d y en aquella bia y forma que de

derecho y mejor podia y debia daba y dio posecion de las

dichas setecientas quadras de tierras al dicho Garcia

Her(nande)z de Caceres conforme al titulo y m(erce)d que de las dichas

tierras tiene la qual dicha posesion dijo el dicho jues

daba al susodicho actual rreal corporal belquasi y

en señal de la dicha posesion le tomo por la mano y le paseo

por las dichas tierras y el dicho Garcia Her(nande)z de Caceres dijo

que en virtud del poder de que tiene y en su nombre que

tomaba y apreendia y aprendio de mano de su m(erce)d del dicho

jues la dicha posesion segun les dada y en señal dello

corto y arranco unas rramas y yerbas y se paseo por

por las dichas tierras y dijo a los q(ue) presentes estaban

$\mathrm{q}(\mathrm{ue})$ se fuesen dellas y pidio al dicho jues le mandase dar

por testimonio de como tomaba y apreendia la di

cha posesion quieta y pasificamente sin con

tradicion de persona alguna que ende estubiese

y el dicho jues se lo mando dar y dijo q(ue) le amparaba y am

paro en la dicha posesion de las dichas setecientas

cuadras de tierras y mandaba y mando que dellas ni en

parte dellas no sea desposeido ni despojado sin primero

ser oydo y uencido por fuero y derecho so pena de d[roto]

cientos pesos de oro para la camara de su ma[roto]

y gastos de just(ici)a en que le doy por condena[roto] 
fs. 43

contrario haciendo y yo el dicho escribano nombrado doy fee

q(ue) el dicho Garcia Her(nande)z de Caceres tomo la posecion del dicho jues

de las dichas setecientas cuadras de tierras quieta y pasifi

cam(en)te sin contradicion y a lo qual fueron presentes por testigos el capitan

Gaspar Espindola de la Cueba y Diego Laso de Balcacar

y don $\mathrm{He}$ (rnand)o? cacique prencipal del dicho balle y lo firmo

de su nombre el dicho jues y el dicho Garcia Her(nande)z de Caceres

de como tomaba la dicha posesion.

[rubricas]

Don R(odrig)o de Rrojas Garcia He(nande)z Caceres

Ante mi escri

baño nonbrado J...Laso

\section{Análisis del documento}

Este título precisa algunos datos que presenta la merced anterior del capitán Diego de Villarroel, donde se incluyen las siguientes tierras indígenas y sus poseedores:

Cacique Liarongo con las tierras de Loncaguin, Colcho y Bueco; Tureulevi, de las tierras de Quillauguecura y Chedengue; Guenchumilla que lo era de Pucaren Malloe y su acequia Quichibuica y finalmente, Calquintegua poseedor de Piguen y Curau. Se menciona al cacique vecino y Millanaume. Asimismo, se señala que a la muerte de Liarongo y sus sujetos, se hizo cargo de Loncavi, el cacique Alonso Rubio.

Los títulos de doña Isabel Osorio de Cáceres fueron dados en merced en Concepción por el gobernador Alonso García de Ramón el 28 de mayo de 1605 , por ser la mujer legítima del benémerito del Reyno, capitán Ramiro Yañez de Saravia. Corresponden a 700 cuadras --otorgadas después de medidas las 300 cuadras del capitán Diego de Villarroel-- de tierras planas ubicadas en el valle de Curimón, nombradas Longocaui y Pagueu que fueron del cacique don Alonso Rubio y Calquintegua.

Queda claro que las tierras nombras de Longocaui y Pagueu ocupaban una superficie mayor a las 300 cuadras proporcionadas al capitán Diego de Villarroel. El documento confirma que sus respectivos caciques eran don Alonso Rubio y Calquintegua, respectivamente. Permanece la duda de si don Alonso Rubio es un sucesor consanguíneo de Liarongo, o es una persona de otro linaje que se hace cargo del centro ceremonial. En cualquier caso no hereda las tierras agrícolas de Colcho y Bueco del cacique Liarongo que le habrían correspondido de ser su sucesor directo. Cabe la posibilidad de que los documentos no mencionen estas dos últimas tierras por considerar que están incluídas dentro de las de Loncocaui. Respecto a Calquintegua se señala que es poseedor de las tierras de Pagueu, lo que marca una diferencia con el documento de Diego de Villarroel que lo hace poseedor de las tierras de Piguen y Curau. No es descartable de que Pagueu se trate de la conjunción fonética de estos dos últimos nombres.

Los límites de la merced de doña Isabel son por el oriente, las primeras serranías del actual cerro $\mathrm{La}$ Mesa o Mercachas; por el norte los Paredones del Inga o Curapilu y las tierras del capitán Francisco Saenz de Mena; por el poniente la acequia antigua y tierras del cacique Alonso Millanaume y una acequia secundaria que salía de la anterior de un indígena importante llamado don Juan Pirulay. Este último por su terminación ay supone una raiz kunza y puede tratarse de un descendiente de mitimae llegado a la zona durante la fase expansiva 
del Tawantinsuyu, lo denota el carácter multiétnico de esta zona del valle. Finalmente, por el sur, la merced limitaba con el estero Pocuro, el camino real de Santiago a Cuyo y las cordilleras de Chacabuco. En relación al camino real cabe informar que fue efectuado siguiendo el trazado del camino inca trasandino del valle de Aconcagua.

Se desea destacar el hecho de que las tierras se llamen Loncocaui o Loncavi, derivación de las voces indígenas Lonko cawin o Lonko cavi es decir lugar de borracheras ceremoniales y de cabeza de cavi. Ambas expresiones aluden al hecho de que en este sector del valle, se concentraban las actividades políticas, sociales y religiosas más importantes del cavi.

Al respecto cabe mencionar que el Cabi o Cavi fue reconocido por los primeros españoles en llegar a Araucanía, tales como el gobernador Pedro de Valdivia, el primer cronista Gerónimo de Bibar, Mariño de Lobera y otros, como un organismo político multifuncional que agrupaba entre 1.500 y 3.000 miembros, es decir unas 400 familias, a cargo de un cacique principal. Esta opinión fue recogida por historiadores contemporáneos como Zapater (1997:446-449) quién destaca el rol del levo, por sobre cualquier otra estructura mapuche prehispánica, enfatizando sus funciones económicas, sociales, judiciales, militares y religiosas. Esta unidad política equivalía a una pequeña tribu o parcialidad con su territorio propio y su centro de reuniones rituales llamadas cahuín. Siete u ocho cabis conformaban un lebo. Usualmente los cabis "se unían solamente ante un peligro exterior, como fue la concertación de alianzas para rechazar la expansión incaica" (Zapater 1997).

Debido a que el conquistador español Pedro de Valdivia atacó y venció en su fortaleza al señor de la mitad de arriba del valle de Aconcagua en 1541 (Bibar 1966 [1558]) lo que marcó el inició de un proceso de disgregación y merma de la población originaria, adjudicándose para sí la encomienda del valle de Aconcagua, llevándose consigo a la Araucanía al cacique Michima Lonko, como capitán de indios amigos, es casi seguro que el Cabi desapareció definitivamente al cabo de pocos años. En consecuencia, se estima altamente probable que este espacio reclamado por los beneméritos del Reyno, Diego de Villarroel e Isabel Osorio de
Cáceres correspondiera al asiento principal del señor del valle y su linaje y que, a la llegada de Pedro de Valdivia, fue conocido como Michimalonco.

Ahondando aún más esta hipótesis, proponemos que el caserío principal del linaje del señor de la mitad de arriba y su centro ceremonial --lonkocawin-- se ubicaba donde los documentos identifican los Paredones del Inga. De acuerdo a nuestros reconocimientos de terreno, este lugar coincide con la actual hacienda Santa Rosa, donde los padres Agustinos construyeron un hospicio a principios del siglo XVII. Para mayor abundamiento, postulamos que los edificios incaicos fueron construidos en el lugar para control de la cabecera del cavi y conjuntamente se abrió un canal para ampliación del riego de la zona.

EI hecho que estas pertenencias fueran el asiento del Cavi principal del Aconcagua explicaría el porqué allí se emplazaron las instalaciones incaicas de la importancia de cerro Mercachas o El Castillo y también, el porqué personajes beneméritos de la jerarquía de Isabel Osorio de Cáceres, el capitán Diego de Villarroel, el capitán Bartolomé de Escobar, el capitán Francisco Sáenz de Mena y Hernándo de Escudero, solicitaron las primeras tierras del curso superior del valle en dicho sector. Desde este punto estratégico de gran potencial agrícola y ganadero era posible controlar el tráfico intra y extraregional.

Finalmente, en la posesión se proporciona como testigo al cacique principal del valle de principios del siglo XVII, don Hernando. Cabe destacar que hacia la fecha en que se otorga la merced ya estaban constituidos los pueblos de Curimón, en la margen sur, y Aconcagua en la margen norte del río de ese nombre, situación que no estaría presente en la primera merced otorgada a Diego de Villarroel en 1602. Esto podría estar señalando con gran precisión el período en el cual los españoles conformaron esta nueva realidad jurídica del valle, coincidente con el otorgamiento de los primeros títulos y de la llegada del agrimensor Ginés de Lillo y, consecuentemente, con el desplazamiento de los indígenas de sus lugares de origen. 


\section{Arqueología del Período Intermedio Tardío y Tawantinsuyu}

Existe poca información publicada sobre la arqueología del sector de nuestro interés. Sin embargo, reconocimientos efectuados por Carlos Coros, Rodrigo Sánchez, Nuriluz Hermosilla y Rubén Stehberg, han demostrado la existencia de numerosos sitios arqueológicos de estos períodos en el área considerada. Una prospección efectuada en el curso medio y superior del estero Pocuro, demostró la presencia de diversas instalaciones a lo largo de su desarrollo. La mayoría de ellas tiende a concentrarse en sectores de terrazas y rinconadas adyacentes al río. Otras se sitúan en la falda de los cerros de la zona o en sus planicies agrícolas adyacentes. Existen algunas instalaciones emplazadas en sectores más altos, como naciente del estero e incluso en la cumbre de los cerros del área. La datación de restos cerámicos procedentes de algunos sitios del período Tawantinsuyu demuestran que ellos se establecieron sobre yacimientos pre-existentes.

De acuerdo a los antecedentes disponibles el siguiente patrón de poblamiento puede establecerse para el período Tawantinsuyu:

- Instalación de cerro Mercachas: en situación dominante, tanto por su envergadura arquitectónica como por su elevación de más de $500 \mathrm{~m}$ sobre el nivel del valle y su ubicación estratégica, con amplio dominio del curso medio-superior del valle agrícola de Curimón y Aconcagua, destaca la instalación de este nombre. Aparte de lo anterior, el cerro sobresale por su cumbre amesetada de $300 \mathrm{~m}$ de longitud, lo cual habría llamado la atención a la población tardía local, que grabó algunos petroglifos, destacando el motivo "círculo con punto central", en uno de los bloques superficiales emplazados en el extremo norte de la meseta. Este petroglifo no tiene relación con la instalación diaguita-incaica de la cumbre, ubicándose fuera de su sistema de muros perimetrales. No cabe duda que la forma tan particular de este cerro, especialmente su extensa explanada de cumbre, llamó la atención de los nativos del lugar. En forma hipotética se postula que fue elegido como cerro sagrado, seguramente cerro Tren-Tren, puesto que su forma era especialmente apta para recibir y acomodar a la población local en caso de que sobre- viniera un diluvio, sacralidad que pudo remarcarse mediante los mencionados petroglifos. Un levantamiento topográfico y estudio preliminar del sitio es publicado por Sanguinetti (1975), quién no duda en calificarla como una fortaleza de origen diaguita-incaica.

- Sitios al piedemonte del cerro Mercachas: prácticamente a lo largo de todo el contorno de este cerro se emplazan cementerios diaguita-incaicos destacando El Sauce en su base nor-poniente; Los Quillayes, en su base oriente; Santa Rosa en su base sur-poniente y San Vicente, en la base poniente. Del material extraído de El Sauce destacan dos aríbalos, uno de ellos con decoración fitomorfa, dos copones o tazones de pie, un plato hondo decorado y tres ollas con dos asas cinta sin decoración. Los Quillayes sobresale por la presencia de objetos metálicos en cobre y un plato ornitomorfo. Santa Rosa corresponde a un cementerio de túmulos de origen pre incaico que continúa ocupándose durante el período de contacto siguiente. Los fechados TL de este sitio son: 745 $\pm 75,665 \pm 70,530 \pm 60$ y $500 \pm 60$ años AP, siendo estos dos últimos del período de contacto incaico. Aporta una rica colección de cerámica constituida por aríbaloides, copones o tazones de pie, platos ornitomorfos, platos grandes, ollas y jarros sin decorar. En la Escuela Pascual Barburizza, San Vicente, aparece en una excavación agrícola una botella doble con asa puente finamente decorada con motivos trícromos fitomorfos. Estos materiales integran la colección del Museo Arqueológico de Los Andes. Un completo informe sobre estos sitios se proporciona en Stehberg y Coros (1999).

- Instalación de El Castillo: corresponde a un extenso asentamiento habitacional y funerario emplazado en un sector agrícola entre el estero Pocuro y la base de uno de los cerros septentrionales del cordón de Chacabuco, en el acceso norte del paso del mismo nombre, unos $5 \mathrm{~km}$ hacia el $\mathrm{SO}$ del cerro Mercachas. Se encuentra completamente destruido por los trabajos agrícolas, pero la instalación contó con extensos muros de pirca doble que prácticamente han desaparecido. Del sitio se ha rescatado algunos platos ornitomorfos y más de un centenar de fragmentos cerámicos decorados y sin decorar y trozos de adornos e instrumentos de piedra. El material exhibe fuerte influencia 
diaguita-incaica. De acuerdo a los fechados TL obtenidos a partir de la alfarería de $755 \pm 90,910$ $\pm 85,830 \pm 80$ y $725 \pm 75$ años AP se infiere que el sitio es ocupado con anterioridad al arribo de los contingentes incaicos.

- Red vial incaica: es de gran importancia el hecho de que el sector esté atravesado por una red vial longitudinal y transversal. Los caminos transandinos corren por la margen sur y norte del río Aconcagua hacia la cordillera andina. En el sector de estudio quedan separados por el cerro Mercachas, que las controla visualmente, hasta su empalme con el camino longitudinal. Se establece un punto nodal cerca de la actual ciudad de San Felipe, donde existió un importante asentamiento Tawantinsuyu (Bellavista) y otro en el acceso al Paso Chacabuco, cercano a la instalación de El Castillo, antes mencionada.

\section{Significado de estos hallazgos}

La envergadura de los sitios mencionados, la fuerte presencia de la red vial y la calidad de los materiales extraídos de los cementerios sugieren que esta zona tuvo un alto interés para el Tawantinsuyu. Podría pensarse que para el Estado inca era fundamental controlar la puerta de entrada y salida del valle de Aconcagua, hacia la vertiente oriental de Uspallata y Cuyo. Sin embargo, ello no explica la magnitud y altitud de la instalación de cerro Mercachas, que se eleva desafiante sobre el valle y que constituye una novedad, luego de que por más de $800 \mathrm{~km}$ de territorios con valles transversales similares e importantes conexiones viales trasandinas, no se levantara ninguna instalación de este tipo. Es más, existe una segunda fortaleza semejante en la parte inferior del valle de Aconcagua, el pucará de cerro Mauco, que tiende a reforzar la idea de que algo distinto acontecía en el valle.

\section{Integración de la información etnohistórica y arqueológica}

La hipótesis que se plantea en este ensayo --a partir de la información recabada por la arqueología y la etnohistoria-- es que en el Período Agroalfarero Tardío inmediatamente preincaico incaico, residía una población nativa importante en este sector de valle colindante al cerro Mercachas, al man- do de un cacique principal que vivía en el sector. Las actividades económicas estaban centradas en una agricultura hortícola de poco desarrollo, complementada con la caza y recolección vegetal, donde no faltaba la provisión estacional de productos de origen marino (pescados y mariscos secos, algas). La importancia relativa de esta comunidad y de su cacique residía en que se ubicaba estratégicamente en un punto tal del valle, que controlaba el acceso a las veranadas y minerales de la cordillera y el paso a la vertiente oriental andina. Las aguas que regaban todo el valle pasaban por el medio de sus tierras y nacían en las cordilleras de su propiedad. De tal suerte, que simbólicamente esta parcialidad controlaba los pastizales y vegas estivales, las fuentes minerales y vidrios volcánicos, el origen del agua, los accesos a las altas cumbres sagradas y el comercio trasandino. Culturalmente esta población nativa era mapuche y hablaba mapudungun pudiéndose calificar de sociedad segmentada por presentar unidades autónomas vinculadas por parentesco y rivalidades entre sí (Zapater 1997:445). El mito del diluvio estaba presente y se estima que, por las características tan particulares del cerro Mercachas, con su extensa explanada de cumbre y su altura relativa sobre el valle, pudo ser elegido como cerro Tren-Tren, como lugar propicio para salvarse de las aguas. Los petroglifos preincaicos e incaicos grabados en los afloramientos rocosos del sur de su cumbre confirman la sacralidad atribuida al lugar. La principal estructura socio-política-militar estaba conformaba por el Cabí, siguiendo el modelo mapuche prehispánico.

La preeminencia de un cacique fue registrada por el primer cronista español al describir que el valle de Aconcagua tenía dos señores: Michimalongo en la sierra y Tanjalongo, en la costa y que el primero prevalecía sobre el segundo (Bibar 1966 [1558]). Sin embargo, aún no se ha establecido si este sistema dual ya existía en tiempos pre Tawantinsuyu o surgió como consecuencia de aquel.

Nuestra hipótesis agrega que durante el período Tawantinsuyu, los contingentes diaguita-incaicos se apoderaron del cerro sagrado local Mercachas, y construyeron allí una gigantesca guaca-fortale$\mathrm{za}$, con la cual dominaron simbólicamente la guaca local y por su intermedio al levo colindante. 
Tras las negociaciones y arreglos que siguieron, el cacique principal aceptó las condiciones que se le plantearon y que deben haber sido muy parecidas a las acordadas en otras provincias: proveer de mano de obra para el servicio de mita y aceptar la introducción de instituciones estatales en su área. A cambio de ello, el cacique era reconfirmado en su cargo y veía aumentado su poder, al agregársele nuevos símbolos de estatus como el fino vestuario de lana de vicuña procedente del Cusco, la invitación a sentarse a comer en la misma mesa del Inca o el honor de enviar a su hijo a educarse a una capital provincial. Puede que justamente este fuera el momento en que el cacique principal del Cabi se constituyera en señor de la Sierra o de la mitad de arriba, Michima Lonko, en contraposición al señor de la mitad de abajo, Tanja Lonko, tal como quedó registrado por el primer cronista español (Bibar 1966[1558]).

El hecho de que dos benémeritos del Reino se disputaran las tierras de Longocabi o Loncauin, que respectivamente significan cabeza del cavi y lugar de junta para beber y cuyos deslindes son discernibles en la actualidad, estaría indicando el lugar exacto donde estuvo el asiento del cacique o señor de ese cavi, entre la hacienda Santa Rosa por el norte y el estero Pocuro por el sur, en la comuna de Calle Larga. Asimismo, sugirió el documento que el cacique Liarongo, sería el último sucesor de dicho linaje, fallecido hacia fines del siglo XVI.

Con los mitayos disponibles los mitimaes diaguitaincaicos procedieron a iniciar la construcción de la red vial, del canal de regadío "Quichibuica", de la instalación "Paredones del Inga", de la instalación de El Castillo y de la ampliación de la gua$c a$-fortaleza de cerro Mercachas. Respecto a esta última, cabe mencionar que la función de fortaleza propuesta por Sanguinetti, (1975), tiene el inconveniente de que la instalación se encontraba en una posición muy elevada y alejada de la población local y no contaba con recursos de agua, lo cual hacía inoperante su utilización. Sin embargo, presentaba un diseño arquitectónico de pukara, lo cual nos permitió sugerir una función alternativa de guaca-fortaleza, donde la apropiación de un espacio simbólico era tan o más importante que lo funcional. Respecto a la red vial existe información documental de que existió un puen- te colgante incaico a la altura de Salto del Soldado (Stehberg et al. 1999) y es altamente probable que haya existido otro frente al lugarejo Tambo, cerca de San Felipe.

Una guaca-fortaleza de origen diaguita-incaico de características muy semejantes existiría en el sector costero del mismo valle. Allí se encuentra emplazada sobre la cima del cerro Mauco, una instalación similar, a $500 \mathrm{~m}$ sobre el nivel del valle circundante con una explanada de cumbre similar a la del cerro Mercachas, por lo cual es dable pensar que fuera un cerro sagrado para la población local. Refuerza esta idea el significado de la palabra Mauco que en mapudungun significa Agua de Lluvia, aludiendo al hecho de que cuando este cerro se nubla, invariablemente sobreviene lluvia, indicando con ello que allí tenía residencia el espíritu de la lluvia o el hacedor del agua.

La planicie costera que se extiende hacia el Poniente es denominada por los documentos tempranos como Puchun Cabi, aludiendo a que en el sector existió a la llegada del conquistador español un cavi costero, es decir una agrupación de más de 400 familias, seguramente bajo el dominio del Tanjalonko. Esta denominación se ha conservado hasta el presente. De acuerdo a nuestra hipótesis, el Tawantinsuyu se habría apoderado del cerro sagrado de Mauco, previo a ejercer su control sobre el cavi de Puchun.

Hasta donde llegan nuestros conocimientos actuales, esta forma tan particular de someter a los cacicazgos y señoríos locales fue característica del Tawantinsuyu en otras partes del Estado. Sin embargo, en Chile se postula por primera vez. Hacia el norte, en los amplios valles transversales del norte semiárido chileno hasta el valle de Huasco, estas instalaciones de guaca-fortaleza no se han encontrado (Stehberg 1995). En cambio, en este mismo valle y hacia los territorios de más al Sur se reconocen numerosas instalaciones fortificadas en cerros-isla (La Compañía, Chada) o cerros-espolones como El Tártaro, Catemu y Chena (Sánchez com. pers. 1999) de alturas inferiores a los $100 \mathrm{~m}$ sobre el nivel del valle circundante, que presentan un importante simbolismo en su emplazamiento pero que no han mostrado evidencias de haber sido guacas locales preincaicas e incaicas. 


\section{BIBLIOGRAFIA}

BIBAR, G. Crónica y relación copiosa y verdadera 1966 [1558] de los Reynos de Chile. Edición Facsimilar del Fondo Histórico Bibliográfico José Toribio Medina, Tomo 2, Santiago.

FARRINGTON, I. Ritual geography, settlement patterns 1992 and the characterization of the provinces of the Inka heartland. World Archaeology vol, 23(3): 368-386, Routledge.

1998 El concepto de Cusco. Tawantinsuyu 5:53-59, Sidney.

1999 El Shinkal: Un cusco del Kollasuyu. Congreso Nacional Arqueología Argentina. Tomo 1:53-62, La Plata.

PLANELLA, M. y R. STEHBERG. Intervención inca en un 1998 territorio de la cultura local Aconcagua de la zona centro-sur de Chile. Tawantinsuyu 3:58-78, Sidney.

RUIZ, C. Glosario de topónimos. Valles, 4:1191998 123, Museo de La Ligua.

SANGUINETTI, N. Construcciones indígenas en el cerro 1975 Mercachas (Departamento de Los An- des, provincia de Aconcagua). Anales del Museo de Historia Natural de Valparaíso, vol. 8:129-139, Valparaíso.

STEHBERG, R. Instalaciones incaicas en el norte y 1995 centro semiárido de Chile. Colección de Antropología. Centro Barros Arana. Dirección de Bibliotecas, Archivos y Museos, Santiago.

STEHBERG, R. y C. COROS. Sitios arqueológicos incaicos 1999 del curso medio-superior del valle de Aconcagua. Tawantinsuyu 4 (en prensa).

STEHBERG, R., G. SOTOMAYOR y R. LEON. Mercedes de 1998 tierras al Capitán Diego de Villarroel: Aportes a la arqueología, historia y toponimia del valle de Curimón. Valles. 4:95-125, Museo de La Ligua.

STEHBERG, R., H. NIEMEYER y C. COROS. Investigacio1999 nes de la red vial incaica en el sector de Salto El Soldado (Valle de Aconcagua, Chile Central). Actas del XII Congreso Nacional de Arqueología Argentina, pp. 307-324, La Plata.

ZAPATER, H. Huincas y mapuches (1550-1662). Edi1997 ciones Historia 30:441-504. Santiago. 


\section{Normas Editoriales para la Revista Estudios Atacameños}

\section{Generalidades}

1. Enviar el manuscrito en disquete, escrito en programa Word, y una copia impresa en papel a nombre de:

Hans Gundermann

Editor General de Estudios Atacameños

Instituto de Investigaciones Arqueológicas y

Museo R. P. Gustavo Le Paige S. J.

(IIAM), Universidad Católica del Norte

Correo San Pedro de Atacama

II Región - CHILE

Email: museospa@entelchile.net

2. El texto deberá estar escrito en letra Times New Roman tamaño 12.

3. El escrito, considerando todas las secciones e incluyendo bibliografía y anexos, no deberá sobrepasar las 35 páginas tamaño carta, a espacio simple.

4. Es responsabilidad de los autores atenerse a estas normas, pulir la redacción y revisar la ortografía.

\section{Normas Básicas}

\section{Secciones del manuscrito:}

Resumen en español (5 a 10 líneas)

Abstract en inglés (5 a 10 líneas)

Palabras claves

Texto

Agradecimientos

Anexos

Bibliografía

2. Título del trabajo: letra Times New Roman tamaño 18 , minúscula, centrado.

3. Autores: el nombre o nombre deberá(n) alinearse en el margen derecho. Deberá indicarse: institución, dirección postal o dirección electrónica, las que deberán ir al pie de página, consignadas como notas numeradas.
4. Texto: podrá desarrollarse en segmento que, según la inclusión de unos en otros, irán designados con títulos primarios, secundarios y terciarios.

Los títulos primarios deberán ser escritos en letra minúscula, negrita, alineados a la izquierda.

Los títulos secundarios deberán ser escritos en letra minúscula, normal y alineados a la izquierda.

Los títulos terciarios deberán ubicarse al inicio del párrafo correspondiente, en letra cursiva y separados del texto por un punto seguido.

Los títulos de Resumen y Abstract deberán ir en mayúsculas y en negrita.

Los párrafos no deberán tener sangría.

5. Notas al pie de página: todas las notas deberán ir al pie de página y numeradas correlativamente en números arábicos $(1,2,3 \ldots)$ en superficie, continuando la secuencia iniciada por los datos de autores.

6. Tablas y Gráficos: todas las tablas y gráficos deberán ser numerados en el orden en que son mencionados en el texto. Se deberá proveer un título corto para cada tabla y gráfico, en letra minúscula, negrita, alineado a la izquierda.

7. Figuras (fotografías, mapas, dibujos): deberán ser numeradas secuencialmente, en el mismo orden en que son citadas en el texto y deberán ceñirse a las mismas especificaciones que las Tablas y Gráficos.

8. Bibliografía: los datos de las referencias citadas deberán ser dispuestos en el siguiente orden: autor(es), año, título, imprenta, lugar de publicación. Los autores deberán ir en 
mayúscula. Sólo la primera letra del título deberá ir en mayúscula. El título de revista, libro o monografía deberá aparecer en cursiva. Se deberá consignar solamente las iniciales de los nombres de los autores; cuando haya más de un autor, solamente para el primero deberá aparecer el apellido antes que el nombre. Todos los artículos de revista deben llevar el número de páginas.

\section{Cita de libro:}

HAMPTON, D. R., C. E. SUMMER y R. A. WEBER, 1978. Organizational behavior and the practice of management. Scott Foresman (Ed.), Glenview, Illinois.

\section{Cita de revista:}

MUNIZAGA J., 1974. Deformación craneal y momificación en Chile. Anales de Antropología 11: 329-336.

Cita de artículo en un libro:

NICHOLS, D. I., 1987. Prehispanic irrigation at Teotihuacán, new evidence: The Tiajinga canals. En Teotihuacán: Nuevos datos, nuevos síntesis, nuevos problemas, E. McClung de y F. C. (Eds.), pp. 133-160. Universidad Autónoma de México, México.

Cita de artículo en un volumen de una serie: KHOL, P. L. 1987. The use and abuse of world systems theory: The case of the Pristine West Asian State. En Advances of archaeological method and theory, vol. 11, M. Schiffer (Ed.), pp. 1-35. Academic Press, San Diego. 